\title{
SONETTI PER L'ARMAMENTO DI UN CAVALIERE: FOLGORE DE SAN GIMIGNANO
}

\author{
Maria Pont
}

\section{APUNT BIOGRĀFIC}

La vida i l'obra de Giacomo de Michele, anomenat Folgore, se situa a San Gimignano, a la Toscana, prop de Siena. Una ciutat tancada per muralles i perfilada per torres amenaçants - se l'anomenava \&San Gimignano dalle Belle Torri»-, amb carrers estrets, amb clans familiars enfrontats com a conseqüència de l'oposició entre la Santa Seu i l'Emperador Frederic I Barbarroja. El poder temporal i el poder imperial es disputaven el dominium mundi. Els güelfs - partidaris de la política papal- i els gibel-lins - partidaris de la política dels emperadors germànics - traspassaven l'enfrontament a les ciutats del centre i del nord d'Itàlia. Un esperit de competició, una acumulació de rivalitats, un seguit d'odis i vendette provocaren un sentit d'inseguretat en l'espai que els feia enemics: la ciutat. Ni güelfs ni gibel-lins tingueren una ideologia precisa; s'oposaren per raons polítiques, en un principi, després s'oposaren per motius de simple divisió de costums. Un antagonisme irreversible, uns es representaven per una flor de lis vermella sobre fons blanc - els güelfs - , els altres per una flor de lis blanca sobre fons vermell - els gibel-lins. Els colors blanc i negre els dividia en dos grups amb forta cohesió social. Eren els Blancs, uns, i els Negres, els altres. Els símbols els varen fer apuntalar en el temps i l'espai fins ben entrat el segle XV. Les ciutats de govern comunal - com és el cas de San Gimignano-mantenien una tendència filopapal entre els seus membres, mentre que els rivals, els gibel-lins, en la major part d'elles, estaven en franca minoria. 
Folgore de San Gimignano es mou en aquest ambient. Era un Blanc, un güelf nat. Així ens ho demostra un document del 25 de gener de 1295 de l'Arxiu de Siena, on hi ha una nota de pagament a un grup de soldats que acompanyaven al comte Orsello, per manament de la cort comunal sienesa a la Cort Pontifícial. Després d'aquest fet no tenim més notícies de Folgore fins deu anys més tard, al 1305, quan ja forma part oficialment de l'exèrcit comunal de San Gimignano. Sota les ordres de Nello Savore prendrà part en el setge de Pistòia. El document, que es troba a l'arxiu comunal de San Gimignano, parla igualment del sou que va percebre Folgore per prendre part a la contesa ${ }^{2}$. El 1332, Giacomo de Michele ja ha mort. En dos documents de l'arxiu de San Gimignano de l'esmentat any se cita els aheredes Domini Folgoris» i un tal *Nicolus gener Domini Folgoriss. Molt poques dades per establir la durada en aquest món del nostre personatge. Ens resta, però, la seva obra literària. Folgore de San Gimignano era un poeta. Els seus trenta-dos sonets ${ }^{3}$ ens ho constaten. L'activitat literària de Folgore es pot concretat en un període cronològic que va des del 1295 al 1317. El corpus de cinc sonets que encapçala la seva obra sota el títol de Sonetti per l'armamento di un cavaliere ens donen peu a establir la data de 1295 com a començament dels seus escrits poètics. Quan marxa amb una colla de soldats, acompanyant Orsello a la cort pontifícia, apareix el seu nom Folgori olim Michaelis sense l'acompanyament de Domini. Folgore enca-

1 attem LXXXVII libr. die dicta infrascriptis militibus stipendiariis Comunis Senarum, ultra eorum soldum, pro vigintis diebus ad rationem trium solidorum per diem pro quolibet eorum per apodixam Dominorum Novem. Quorum nomina sunt (...) Folgore Michaelis... (amb d'altres noms de soldats) qui ibunt cum Domino Comite Urso ad Curiam Papae per apodixam Dominorum Novem.x 25 de gener de 1295, Libri di Biccherna, Anxiu de Siena.

2 altem XXIIII' sol. Folgori olim Michaelis, pro suo salario sex dierum, quibus pro Communi stando in exercitu facto Pistorii mandato Nelli Savori Capitanei peditum Communis ibidem existentium, venit et stetit veniendo stando et redeundo ad dictum exercitum ad Sanctum Geminianum in servitium dicti Communis, videlicet ad rationem sol. IIII' ${ }^{\text {ar }}$ pro die quolibet de quibus non erat ei satisfactum. $>28$ de setembre de 1305 , doc. nn. 239. Arxiu de la Comuna de San Gimignano (Florència).

${ }_{3}^{3}$ Recollits amb el títol: Folgore de San Gimignano: Sonetti (a cura di Giovanni Caravaggi), Giulio Einaudi Editore, Torino 1965. L'índex és el següent: Sonetti per l'armamento di un cavaliere (5); Sonetti della eSemanas (8); Sonetti dei Mesis (14); Sonetti politici e moraleggianti (5) i Sonetti di dubbia attribuzione (3). 
ra no havia estat anomenat cavaller. És possible que acompanyés el seguici com a escuder, o com un jove encara no iniciat que segueix al grup armat en incursions soltes. El 1308 se'l troba encara com un donzell a la tropa d'un vigorós güelf florentí, Carles $\mathrm{Ca}$ vicciuoli, que fa la guerra amb l'ajut dels soldats de San Gimignano a la ciutat de Volterra 4 . El 1317, data del tractat de pau entre Robert d'Anjou amb la força gibel lina de Pisa, Folgore escriu dos sonets de to polític recordant la derrota güelfa de 1315 en la batalla de Montecatini ${ }^{5}$. Folgore ja escriu com una persona iniciada en la guerra, com un cavaller (Dominus).

El que ens interessa en aquest treball es donar a conèixer el primer vessant del nostre poeta comunal. Reflexionarem sobre el corpus de Sonetti per l'armamento di un cavaliere. Els situem cronològicament entre 1295-1308. No podem perfilar més. Es tracta de cinc sonets que apunten els trets morals i materials que han de distingir qui vol convertir-se en cavaller. Una Introduzione obre $\mathrm{cl}$ corpus poètic $\mathrm{i}$ un seguit de quatre sonets emmarquen les qualitats i virtuts que ha de mantenir qui vol entrar en el món de cavalleria: Prodezza (Coratge), Umilità (Humilitat), Discrezione (Discreció) i Allegrezza (Alegria) ${ }^{6}$. La descripció iniciàtica per a l'entrada en aquesta esfera omple els versos del nostre autor d'un discurs al-legòrico-estètic, propi del context cultural on es mou. Folgore de San Gimignano respira l'ambient liberal de la cort comunal de la seva ciutat. Donzell encara, vol perfilar en aquests sonets les virtuts cavalleresques del seu món urbà. Es submergeix en un món on el passat - el vigorós passat de la cavalleria medie$\mathrm{val}^{7}$ - pren un altre caire, s'omple d'una aureola lúdica i cromàtica.

4. BERTEU, Un poeta del mondo comunale: appunti su Folgore da San Gimignano, p. 88. Milã.

5. BERTELI, Un poeta del mondo comunale..., p. 88. Milà.

6 Titols dels cinc sonets que configuren el corpus Sonetti per l'armamento di un cavaliere. A Folgore de San Gimignano: Sonetti, pp. 27-31.

7 Em sembla important de citar tres estudiosos del tema de la cavalleria a I'Edat Mitjana: E. KOHIER, L'aventure chevaleresque, N.R.F. Gallimard 1974; FRANCO CARDINI, Alle radici della cavalleria medievale, Il pensiero storico, Lanuova Italia Editrice. Firenze 1982, i J.E. Rurz DOMÉNEC, La caballería o la imagen cortesana del mundo, Collana Storica di Fonti E Studi (diretta de Geo Pistarino), Gżnova 1984. 


\section{JUGAR COM A FENOMEN CULTURAL}

El caràcter lúdic en la història, jugar com a fenomen cultural, ha format part d'aquesta com aquell element primari, com aquell element-inicial de qualsevol desenvolupament sòcio-cultural ${ }^{8}$. L'individu l'assumeix com a comportament primari del món on es mou. Les representacions agonals originades per la mateixa naturalesa humana fan del joc un fenomen cultural prou important com per no deixar-lo de banda en l'anàlisi del comportament de l'individu o dels individus en societat. Quan «es juga» $-i$ aquest és el cas dels cinc sonets per l'armamento di un cavaliere - es perd la noció de la realitat immediata. El tàndem realitat-idealitat pren en la ploma de Folgore un caire de joc, culturalment parlant. Un joc, els antecedents reals del qual hem de buscar en una altra esfera: l'aristocràtica; en una altra societat: la feudal; i en una altra data: 1170 . El pas del temps ha transformat el fenomen cultural cavalleresc en un joc. El pas del temps l'ha traspassat a una altra esfera: la cort comunal de San Gimignano; a una altra societat: la urbana; i a una altra data: 1295-1308. Folgore se sent partícip de tota una einstituciós fonamentada en l'honor i la virtus, on cal introduir-se ritualment, mitjançant un acte, l'adoubement', l'armament del cavaller. La cavalleria com a institució anirà adaptantse a les mentalitats de la societat. L'espai on Folgore deixa anar la seva imaginació és un espai urbà. El fet de ser armat cavaller, en aquest espai, ja no serà la resposta a una societat agressiva com ho és la feudal. La realitat s'ha distorsionat i s'ha convertit en un joc. La realitat ha distorsionat la imatge de la cavalleria medieval. Jugar ha fet emergir en el món urbà - a la comuna de San Gimignano- un grup d'individus portadors d'armes que han de ser coratjosos, humils, discrets $\mathrm{i}$ alegres.

Si la cavalleria medieval emergia com un estament bel-licós i guerrer on el pillatge es convertia en el modus vivendi, la seva imatge s'ordenarà d'una altra manera i prendrà només la seva forma ritual on traspassada en un altre espai s'aglutinaran costums, gestos i actituds del passat. D'aquesta manera hem de veure els

8 J. HuizIngA, Homo Ludens, Alianza/Emecé, Madrid 1972.

9 Pel tema de l'adoubement i el seu vocabulari: J. FLORI, Semantique et Société Médiévale. Le verb adouber et son évolution an XII siècle, Annales E.S.C. 1976, pp. 915-940 i del mateix autor: Qu'est-ce qu'un bacheler? Étude historique de vocabulaire dans les chansons de geste du XII siècle, Romania 96, 1975. 
cinc sonets de Folgore. No hem de buscar en aquest «ritu iniciàtic d'armament d'un cavallers un passat mític i ancestral com en l'adoubement medieval. No busquem el cavaller invencible, invulnerable. El cavaller del qual ens parla Giacomo de Michele el 1295 serà una necessitat lúdica del món ciutadà, de la mentalitat urbana. Serà la necessitat social de poder-se anomenar d'una manera determinada, carismàtica i prestigiosa: Dominus. El fet de dur el qualificatiu de Dominus davant del nom crearà la fixació d'un rol determinat - el de la guerra, el de les armes - en el món ciutadà. La mateixa paraula Dominus i no pas miles du immersa en ella mateixa el pas del temps, la distorsió dels valors passats. La paraula Dominus aglutina en cl seu contingut dos valors «meraveIlosos»: noblesa i cavalleria. Dos valors que adoptaran en el món urbà aquells qui són portadors d'armes. Ser armat cavaller en el món ciutadà ja no comportarà el sentit de vassall, sinó el de servei. S'ha de servir una comunitat i els valors morals han de ser justificatius de la nova realitat social.

\section{LA JOVENESA}

El primer sonet, a mode d'Introduzione, obre les portes al subjecte de l'acció, a l'individu que prendrà les armes: un donzello. Un primer tret per situar el discurs de Folgore en el pla cortesà dins del món urbà. L'encapçala el següent vers: Ora si fa un donzello cavalieri I Ara que un jove és armat cavaller. Aquest primer vers apunta el primer tret enecessaris per a ser armat cavaller, cal ser donzello, cal ser jove ${ }^{10}$. La «colla» de Folgore i ell mateix se sentien iuvenes. No és pas una qüestió d'edat sinó una actitud, una manera de fer 1 de ser compartida per un grup solidari en el seu comportament. Ser jove, en l'espai urbà italià del segle XIII, ja no és un substantiu abstracte que designa una qualitat moral individual. Ês un substantiu col-lectiu ${ }^{11}$. Un col-lectiu que aglutinarà

10 jove $=$ iuven. Cal remarcar els estudis fets sobre els iuvenes, la iuventus o la jeunesse per E. KOHLER. Sens el fonction du terme njeunesse , dans la poésie des troubadours: J. DEMONY. Jovens: the notion of yousb among the trobadours, its Meaning and Source, a Medieval Studies, t. XI. 1949 i G. DUBY, *Au XII siècle: les jeunes dans la societé aristocratique» a Annales E.S.C. T. XIX, 1964.

11 Segons els estudis sobre la iuventus de J. DEMONY, Jovens: the notion of youth among the trobadours... 
en el seu si tot un conjunt de qualitats morals i estètiques: l'aventura, l'amor, l'alegria, la llibertat. Ser jove serà, doncs, la realitat perfecta de l'ideal cortesà. Un moviment àvid d'ascens i integració social, com ho mostren els tres versos següents que tanquen la primera estrofa del sonet d'Introduzione:

e'vuolsi far novellamente degno

e pon sue terre e sue castell'a pegno

4 per ben fornirsi di ciò ch'c̀ misteri:

primer de tot, mirant de fer-se'n digne castells i terres per escrit consigna

4 per formir-se del que ba de menester:

\section{LA FESTA}

Tot està preparat per començar la festa. L'actitud festiva -o més ben dit la preparació de la festa - conclou el primer sonet d'Introduzione.

annona, pane e vin dà a'forestieri manze, pernici e cappon per ingegno; donzelli e servidori a dritto segno,

8 camere e letta, cerotti e doppieri;

e pens'a molti affrenati cavagli, armeggiatori e bella compagnia,

11 aste, bandiere, coverte e sonagli;

ed istormenti con gran baronia, e giucolar per la terra giudàgli,

14 donne e donzelle per ciascuna via.

queviures $i$ pa i vi pel foraster vedelles $i$ perdius, capons li assigna; donzells $i$ servidors com a bon signe,

8 cambres $i$ llits, $i$ llums al candeler;

i també pensa a tenir molts cavalls, en els torneigs $i$ en I'boste rialler.

11 llances, banderes, picarols $i$ abrigalls, 
$i$ en instruments, $i$ en gent com ha de ser,

i en els joglars que els guitin com vassalls

14 i en dones $i$ donzelles pel carrer.

Folgore enquadra l'armament del cavaller en uns preparatius festius. En un espai cortesà i urbà. En un esperit laic i giocoso. L'autor ens introdueix en un món d'imatges sensuals, cromàtiques i en moviment. En un món sorollós. El fet de prendre les armes un jove en el món comunal comporta soroll i festa. Una festa cortesana. La festa marca els moments importants de la vida dels individus i de les comunitat socials. Assenyala, d'una manera o altra, un triomf social, una preeminència social de qui fa o qui li és dedicada la festa. Es l'ocasió - com ens indica aquest primer sonet- de la prodigalitat, del fast, de la generositat ${ }^{12}$ i la diversió. S'ha de ser generós. Es una actitud social pròpia dels poderosos, dels que se situen més enllà de les muralles de la ciutat, dels aristòcrates, dels feudals. De l'esfera on ha sorgit la cavalleria, el cavaller-noble. Qualitats morals d'una altra esfera, que Folgore traspassa a la realitat urbana. Una vegada més Folgore de San Gimignano adapta el costum ritual laic de l'adoubement: quan un individu entra dins la cavalleria se celebra un acte festiu.

Serà, doncs, aquest primer sonet el que abrigarà sota un caràcter lúdic, cortesà i festiu l'entrada a la cavalleria del jove donzell.

\section{CORATGE, HUMILITAT I DISCRECIÓ}

Els tres sonets que segueixen aquesta Introduzione canvien de to. De la festa es passa a la interiorització moral de qui ha de prendre les armes. Ha de ser virtuós, coratjós, humil i discret. Tres qualitats cavalleresques. El Coratge, entès com la virtut fonamental de la cavalleria, penetrarà en l'ànim del donzell a través d'un personatge femení. Una abraçada amorosa. El nostre autor traspassa el limit real i transfigura l'alegre - la giocosa - vida cortesana. S'oblida per un moment del soroll festiu i de la iovenessa per

$12 \mathrm{~J}$. HeErs. Fêtes. jeux et joutes dans les Sociétés d'Occident à la fin dü Moyen-Age, Conference Albert-Le-Grand 1971, Montreal, PP. 13 i ss. 
interioritzar, idealitzar i transformar cortesia i cavalleria en un diàleg privat, nocturn i sensual.

Veiem el sonet anomenat Prodezza (Coratge):

Ecco Prodezza, che tosto lo spoglia e dice: «Amico, e'convien che tu mudi, per ciò ch'i vo'veder li uomini nudi

4 e vo'che sappi non abbo altra voglia;

e lascia ogni costume che far soglia, e nuovamente t'affatichi e sudi; se questo fai, tu sarai de 'miei drudi

8 per che ben far non t'incresca né doglia*.

E quando vede le membra scoperte, immantenente sí le reca in braccio

11 dicendo: "Queste carni $m$ 'hai offerte:

i'le ricevo e questo don ti faccio, acciò che le tue opere sien certe:

14 che ogni tuo ben far già mai non taccios.

Coratge ve i el despulla, serè

$i$ diu: "Amic, sé que et convé mudar, i per això et despullo amb una mà

4 que, sàpigue-ho, no té cap més voler.

abandona els costums del teu deler. que et cal cansar-te i novament suar; si ho fas aixi el meu cor t'estimarà,

8 perquè fer el bé mai no t'ba de dolen.

I quan li veu els membres descoberts sense pensar-s'bo cau en els seus bragos

11 i fa: "Donat que $m$ 'ba estat oferts:

t'atorgo el do que tenen els audaços

les teves obres contaré, i encerts:

14 la fama escamparà tots els teus passosi.

El següent sonet: Umilità (Humilitat). Aquesta qualitat arriba al jove iniciat de la mà d'una amiga. Altra volta el portador és un personatge femení. La tonalitat d'aquest sonet pren un caire filial, amical, sense desig, sense fusió de cossos - com en el cas del Coratge. La Humilitat ha de ser la seva companya, distant i vigi- 
lant. La Humilitat pren el sentit d'una auto-entrega purificadora. Diu així:

Umilità dolcemente il riceve,

c dice: «Punto non vo'che ti gravi,

ch'e'pur convien ch'io ti rimondi e lavi,

4 e farotti piú bianco che la neve;

$e$ intendi quel ched io ti dico breve,

ch'i'vo'portar dello tuo cor le chiavi,

ed a mio modo converrà che navi.

8 ed io ti quiderò si come meve.

Ma d'una cosa far tosto ti spaccia,

ché tu sai che soperbia m'è nimica:

11 che piú con teco dimoro non faccia.

I'ti sarabbo cosí fatta amica

ch'e'converrà ch'a tutta gente piaccia:

14 e cosí fa chi di me si notrica.

La bumilitat el rep amb dolfor lleu $i$ diu: "No vull que per res passis pena, perquè convé, jo et rentaré en ofrena

4 i et deixarè molt més blanc que la neu;

i escolta axiò que et dic amb llengua breu:

vull dur les claus del teu cor amb cadena.

que vagis com el meu dictat emmena,

8 i et guiaré com si fossis fill meu.

Més de seguida et faig advertiment que l'allivesa és la meva enemiga:

11 no vull veure't amb ella ni un moment.

I aixi et seré una tan completa amiga que el teu tracte a tothom serà plaent;

14 perquè tal fa qui pren la meva espigas.

El darrer sonet d'aquest apartat s'anomena Discrezïone (Discreciō). La Discreció ve de la mà d'un personatge assenyat, en aquest cas el component femeni del portador no es veu clar. Aquest sonet ens situa en un pla de recolliment abans del ritual. Aquesta qualitat, al-legòricament, implica la capacitat d'afrontar $i$ assumir el nou status de cavaller. El recolliment a la vigília de l'armament del jove és en aquest cas la imatge estereotipada de l'adoubement 
medieval: el recolliment en un lloc sant. No és el cas d'aquest sonet. L'espai no és sacre, és cortesà. No hi ha pregàries, no hi ha purificació d'armes, ni cenyiment d'espasa. No hi ha jurament, ni a Déu, ni al seu senyor, ni al seu llinatge. El recolliment es du a terme en una cambra de la cort. No hi ha oració, només pensament. La nit, el descans, les cançons i els plaers el convidaran a dur a terme l'entrada en el món de la cavalleria. Diu així:

\section{Discrezïone (Discreció)}

Discrezione incontanente venne

e sî l'asciuga d'un bel drappo e netto. c tostamente si 'I mette in suo letto

4 di lin, di seta, coverture e penne;

or ti ripensa: infino al dí vi'l tenne cor canti, con sonare e con diletto: accompagnollo, per farlo perfetto,

8 di nuovi cavalier, che ben s'avvenne

Poi disse: aLieva suso immantenente, ch'e'ti convien rinascere nel mondo.

$11 \mathrm{e}$ l'ordine che prendi tieni a mentes.

Egli ha tanti pensier, che non ha fondo. del gran legame dov'entrar si sente,

14 e non può dire: «A questo mi nascondo».

Discreció, que arriba de seguida, me l'eixuga amb un drap immaculat. i prestament en un llit l'ba colgat

4 de fil, de seda i de ploma esmortida: i a meditar fins l'endemà el convida, $i$ amb canfons $i$ plaers al seu costat l'acompanya per fer-ne un acordat

8 perfecte cavaller que es revalida.

Després li diu: "Llevat encontinent. que et convé de renéixer en un nou món.

11 itingues l'ordre que prens ben presentw.

I té tants pensaments en llos pregon sobre el ligam que enfilar ja se sent

14 que no pot dir: "Em fa por $i$ em confon. 


\section{ALEGRIA}

El darrer sonet del corpus poètic s'anomena Allegrezza (Alegria); en ell es barregen alegria i festa. De fet, tanca la roda del discurs de Folgore. El jove ja ha estat adoubé. Ja és un cavaller. Aquest darrer sonet ens transporta a les festes del maggio fiorentino de la Toscana, a les festes de primavera on tot neix. Com ara el nostre cavaller. Tot d'imatges cromàtiques assenyalen l'alegria. La satisfacció de ser un cavaller. El triomf i el joc.

$$
\text { Allegrezza (Alegria) }
$$

Giunge Allegrezza con letizia e festa tutta fiorita che pare un rosaio; di lin, di seta, di drappo e di vaio 4 allor li porta bellissima vesta, vetta, capuccio con ghirlanda in testa, e sí adorno l'ha che pare un maio; con tanta gente che trema il solaio;

8 allor si face l'opra manifesta.

E ritto l'ha in calze ed in pianelle, borsa, cintura inorata d'argento,

11 che stanno sotto la leggiadra pelle; cantar, sonando ciascuno stormento, mostrando lui a donne ed a donzelle

14 e quanti sono a questo assembramento

Venen plegades alegria i festa amb tantes flors que semblen un roser; de seda $i$ lli, de pells $i$ moarê

4 li porten una bella sobrevesta; caputxa, cinta i garlanda a la testa, l'ban adornat que sembla un maig froiter; hi ha tanta gent que en tremola el soler:

8 es fa aleshores l'obra manifesta.

Va amb mitges $i$ xinel. les, $d u$ un cinyell amb una bossa daurada d'argent

11 que es vetu dessaba l'exquisida pell; $i$ canten tots amb el seu instrument $i$ a les donzelles els sembla molt bell;

14 també als que es troben en l'ajustament ${ }^{13}$.

13 La traducció al català dels cinc sonets per l'armamento di un cavaliere és de Xavier Bru de Sala. 
Folgore de San Gimignano impetuós, apassionat, joiôs, festiu. El fervor psicològic i idealista que recobreix els cinc sonets per l'armamento di un cavaliere el va convertir en Domini Folgoris. El seu discurs ens fa pensar que dins la vida comunal $i$ a les seves esferes de poder hi havia alguna cosa d'aristocràtic, d'elegant, de refinat. Ens fa reflexionar sobre un tipus de literatura urbana que no parla del mite de la burgesia. Ens evoca imatges que van més enllà de l'espai tancat de la ciutat i que ens donen una visió on el crit és: Cortezia! Cortesia en un espai que segons la feliç expressió d'Yves Barel: està dins la lògica feudal, però a la vegada es manté aliè a aquesta lògica. La cort comunal, la cavalleria comunal. 